\title{
Message from the President of ASCI
}

\author{
Sachio Kuribayashi
}

Received: 23 October 2011/Accepted: 25 October 2011/Published online: 10 November 2011

(C) Springer Science+Business Media, B.V. 2011

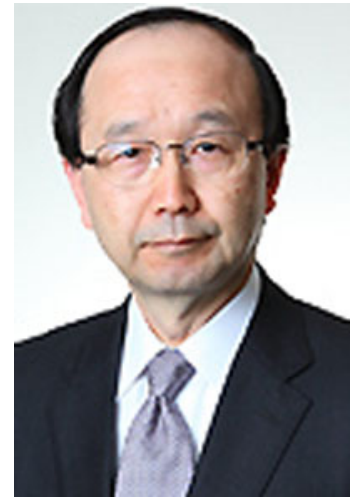

It is a great honor for me to be appointed as the President of the Asian Society of Cardiovascular Imaging (ASCI). As you may well know, ASCI was established on April 29, 2006 with the explicit aim of advancing the science and art of cardiovascular imaging in Asia. Over the past 5 years, Professor Tae-Hwan Lim of Asan Medical Center in Korea has put tremendous effort as President to establish and solidify the organization of the ASCI. I have followed his work closely since June this year, and will endeavor to do my best as the new President for the further advancement of ASCI.

As the main activity of the society, ASCI holds an annual scientific meeting to share the latest

S. Kuribayashi $(\bowtie)$

Asian Society of Cardiovascular Imaging, Keio University

School of Medicine, Tokyo, Japan information and knowledge on cardiovascular imaging, and the 5th congress was successfully held in Hong Kong in June 2011. The 6th congress (ASCI2012) will be hosted in Bangkok, Thailand on June 7-9 next year.

Furthermore, in order to share the ideas and research results of the ASCI with radiologists and cardiologists worldwide, we have started the publication of the ASCI Special Issue in the International Journal of Cardiovascular Imaging since 2009. It is published twice a year and contains original articles, pictorial essays and case reports. In the 2010 issue, the ASCI took the initiative to provide cardiac CT and cardiac MR standard guidelines for the Asian population.

I greatly appreciate the dedication of Dr. Yeon Hyeon Choe, now the adjunct editor for the International Journal of Cardiovascular Imaging, who initiated the ASCI journal project, as well as the contribution of reviewers for the publication of the ASCI Special Issue.

Finally, I would like to express my special thanks to Dr. Johan HC Reiber, Editor-in-Chief of the International Journal of Cardiovascular Imaging, for his understanding and cooperation for the realization of our vision.

Sachio Kuribayashi, M.D., Ph.D. President, Asian Society of

Cardiovascular Imaging

Chairman and Professor of Radiology, Keio University School of Medicine, Tokyo, Japan 